\title{
Spatial Location Competition Strategy of Real Estate Enterprises from the Perspective of Classic Hotelling Model
}

\author{
Chao Zhou ${ }^{1}$, Jie Luo ${ }^{2,}$, Pengfei Zhou ${ }^{3,}$ * \\ ${ }^{1}$ School of Business, Chongqing College of Electronic Engineering,Chongqing, 401331, China \\ ${ }^{2}$ School of Geography and Tourism,Chongqing Normal University,Chongqing, 401331, China \\ ${ }^{3}$ School of Economics and Management, Chongqing Normal University, Chongqing, 401331, China
}

Keywords: Real estate development; Spatial competition; Game strategy; Hotelling model

\begin{abstract}
Spatial location is an important factor in the market competition of real estate enterprises. Hotelling model is one of the most important models, which is based on different spatial locations of firms and provides an analytical framework for firms to determine their location and the nature of their spatial equilibrium in spatial location competition. The market of the real estate market is very similar to the hypothetical market of the classical Hoteling model, which has typical characteristics of spatial competition. Therefore, this paper uses the classical spatial competition model - Hotelling model to analyze the competition of real estate developers, and draws the corresponding conclusions. It is considered that the transportation cost is an important factor affecting the competition and pricing among real estate developers, and the market entry cost and the fixed cost of development also have a significant impact on the competition of developers and the pricing of housing. If the impact of transportation cost on consumers is low enough, the price of housing will be close to the cost price of development, which helps to stabilize house prices.
\end{abstract}

\section{Introduction}

The Hotelling model was established in 1929 by Harold Hotelling to challenge the Edgeworth model. According to Hotelling, the instability of price or output is not the basic feature of oligopoly. Hotelling is the first scholar to study the spatial location of firms. Starting from different spatial locations of firms, he first established a positioning model of duopoly firms in a linear market[1].

In the classical Hotelling model, the physical properties of products are the same, but there are differences in spatial location, which is very similar to the real estate market. Real estate market is a market with product differentiation. This difference is not only reflected in the products developed by real estate developers with their own characteristics, but also in the uniqueness of real estate development location, because in a sufficiently small fixed location, there can only be one development project, which is the spatial difference. Because consumers in different locations have to pay different transportation costs, and they are concerned about the sum of housing prices and transportation costs, not just housing prices[1]. In the real estate market, we can see that consumers not only care about housing prices, but also consider the location and transportation convenience of the house, and make decisions according to the transportation costs between their work place and residence place. This is also an important source of "location theory". This paper attempts to make a preliminary analysis and explanation of this phenomenon and problem by using the classical Hotelling model in the theory of spatial competition.

\section{Establishment of Model and Analysis}

\subsection{Linear city hypothesis}

We abstract the city as a linear city with a length of 1 , and the workplaces of consumers are evenly distributed between 0 and 1 , with a density of 1 . Assuming that two developers have developed two projects at both ends of the city, Project 1 at $x=0$ and Project 2 at $x=1$, the basic characteristics of the two projects are similar. The cost of each project is c. The transportation cost 
of consumers from the workplace to the project is proportional to the distance, and the cost of unit distance is $\mathrm{t}$. In this way, if a consumer at $\mathrm{x}$ buys a house in Project 1 , he will spend the transportation cost of $\mathrm{tx}$ on every trip, and $\mathrm{t}(1-\mathrm{x})$ on the housing in Project 2. Suppose that consumers have unit demand, that is, consumers either consume one unit or consume 0 unit. The consumer's consumption surplus from consumption is $\bar{s}$.

We first consider the equilibrium of price competition between two developers. Suppose that two developers choose the selling price of their own project at the same time. For simplicity, we assume that the total cost of consumption (housing price plus transportation cost) is sufficiently large to allow consumers to buy a unit of product. Let $p_{i}$ be the housing price of Project i, $D_{i}\left(p_{1}, p_{2}\right)$ be the demand function, $\mathrm{i}=1,2$. If there is no difference between the two projects at $\mathrm{x}$, then all the consumers on the left side of $\mathrm{X}$ will buy the house in Project 1 , while the consumers on the right side of $\mathrm{X}$ will buy the house in Project 2 with the demand of $D_{1}=x, D_{2}=1-x$ respectively.

Here, $\mathrm{x}$ satisfies:

$$
p_{1}+t x=p_{2}+t(1-x)
$$

The demand functions obtained by the above formulas are as follows:

$$
\begin{aligned}
& D_{1}\left(p_{1}, p_{2}\right)=x=\frac{p_{2}-p_{1}+t}{2 t} \\
& D_{2}\left(p_{1}, p_{2}\right)=1-x=\frac{p_{1}-p_{2}+t}{2 t}
\end{aligned}
$$

The profit functions are as follows:

$$
\begin{aligned}
& \pi_{1}\left(p_{1}, p_{2}\right)=\left(p_{2}-c\right) D_{1}\left(p_{1}, p_{2}\right)=\frac{1}{2 t}\left(p_{1}-c\right)\left(p_{2}-p_{1}+t\right) \\
& \pi_{2}\left(p_{1}, p_{2}\right)=\left(p_{2}-c\right) D_{2}\left(p_{1}, p_{2}\right)=\frac{1}{2 t}\left(p_{2}-c\right)\left(p_{1}-p_{2}+t\right)
\end{aligned}
$$

The developer i chooses his own price $p_{i}$ to maximize profit $\pi_{i}$. Given $p_{j}$, the two first-order conditions are:

$$
\begin{aligned}
& \frac{\partial \pi_{1}}{\partial p_{1}}=p_{2}+c+t-2 p_{1}=0 \\
& \frac{\partial \pi_{2}}{\partial p_{2}}=p_{1}+c+t-2 p_{2}=0
\end{aligned}
$$

The second order condition is satisfied. By solving the above two first-order conditions, the optimal solution can be obtained as follows: $p_{1}^{*}=p_{2}^{*}=c+t$. The balanced profits of each developer $\pi_{1}=\pi_{2}=\frac{t}{2}$

We can interpret the location difference of consumers as a product difference, which can further explain the transportation cost of consumers. From the final equilibrium profit formula, we can see that the higher the transportation cost, that is, the greater $t$, the greater the difference between products, the higher the equilibrium price and the equilibrium profit $\pi_{i}$. The reason is that with the increase of transportation cost, the substitution of different developers' projects decreases, the monopoly ability of each project to nearby consumers is strengthened, the competition between projects is weaker and weaker, and the sensitivity of consumers to price is reduced, thus the optimal price of each project is closer to the monopoly price. 
On the other hand, when the transportation cost is zero $(\mathrm{t}=0)$, there is a complete substitution between the two projects. At this time, $P_{1}^{*}=P_{2}^{*}=c, \pi_{1}=\pi_{2}=0$, the equilibrium price equals the cost of the developer, and the profit is zero[2]. No developer can set the price higher than the cost.

In the above analysis, we assume that the two projects are located at two extremes of the city. In fact, the equilibrium solution is very sensitive to the location of the project. Next, let's consider another extreme case, if the two projects developed by developers are located in the same location $\mathrm{x}$, that is to say, the projects developed can be completely replaced by each other. At this point, consumers only care about the price, and the result is the same as that in Bertrand model:

$$
P_{1}^{*}=P_{2}^{*}=c, \pi_{1}=\pi_{2}=0
$$

For the sake of generality, we discuss the development of developers at any location in the city. Assume that the Project 1 of developer 1 is located in $a \geq 0$, and the Project developed by developer 2 is located in $1-b,(b>0)$. Assume $1-a-b \geq 0$ (that is, Project 1 is on the left side of Project 2; $a=b=0$ corresponds to maximum differentiation; $a+b=1_{\text {corresponds to minimum }}$ differentiation; that is, it can completely replace each other). If the transportation cost is quadratic, that is, the transportation cost is $t d^{2}$ ( $d$ represents the distance between the location of the consumer and the project), then the demand functions are as follows:

$$
\begin{gathered}
D_{1}\left(p_{1}, p_{2}\right)=x=a+\frac{1-a-b}{2}+\frac{p_{2}-p_{1}}{2 t(1-a-b)} \\
D_{2}\left(p_{1}, p_{2}\right)=1-x=b+\frac{1-a-b}{2}+\frac{p_{1}-p_{2}}{2 t(1-a-b)}
\end{gathered}
$$

The first item of the demand function is the project control "site" ( $a$ is the consumer on the left side of Project 1 and $b$ is the consumer on the right side of Project 2). The second item of the equation is that the consumer situated between the two items is close to half of himself. The third item represents the sensitivity of demand to price variance. At this point, the Nash equilibrium of the price is:

$$
\begin{aligned}
& p_{1}^{*}(a, b)=c+t(1-a-b)\left(1+\frac{a-b}{3}\right) \\
& p_{2}^{*}(a, b)=c+t(1-a-b)\left(1+\frac{b-a}{3}\right)
\end{aligned}
$$

When $a=b=0$, Project 1 is at 0 and Project 2 is at 1 , returning to the first extreme case discussed above:

$$
p_{1}^{*}=p_{2}^{*}=c+t
$$

When $a=1-b$, the two projects are in the same place, that is, at the other extreme case: $P_{1}^{*}=P_{2}^{*}=c$

From the above analysis, we can see that if a city's transportation facilities are developed and the residents' transportation cost from work place to residence place is low enough (that means $t$ is very small), the price of real estate projects can be close to the marginal cost of development. In extreme cases, if the transportation cost is 0 , the price is equal to the marginal cost and the profit of the developer is zero. When the transportation facilities of a city are underdeveloped and the transportation cost is high, the products developed by developers are very different to consumers. When $t$ increases, the competition between the two projects for "the same consumer" is relatively weak[3]. Projects are more "monopolistic" to nearby consumers (which allows developers to raise prices at any time). 
On the other hand, if the projects developed by two developers tend to be in the same position, then the competition will intensify, which will also lead to the price reduction. In extreme cases (competition at the same location) it will lead to the price of the project equal to the cost, and the profit is zero.

\subsection{Game model of linear city hypothesis}

\subsubsection{Non-cooperative game model}

Table 1. Non-cooperative game model of linear city hypothesis

\begin{tabular}{|c|c|c|c|}
\hline \multicolumn{4}{|c|}{ Real estate developer 2 } \\
\hline & & Investment & No investment \\
\hline \multirow{2}{*}{ Real estate developer 1} & Investment & 0,0 & $\prod, 0$ \\
\cline { 2 - 4 } & No investment & $0, \prod$ & 0,0 \\
\hline
\end{tabular}

Because real estate developers are profit-seeking, and a piece of land can not be invested by two real estate developers at the same time unless they cooperate.The extrapolation from table 1 is the game equilibrium is (no investment, investment) or (investment, no investment)[4]. If both developers choose to invest, then they will move to the next stage of the game.

\subsubsection{Cooperative game model}

Table 2 Cooperative game model of linear city hypothesis

\begin{tabular}{|l|c|c|c|}
\hline \multicolumn{4}{|c|}{ Real estate developer 2} \\
\hline & & Investment & No investment \\
\hline \multirow{2}{*}{ Real estate developer 1} & Investment & $\prod / 2, \prod / 2$ & $\prod, 0$ \\
\cline { 2 - 4 } & No investment & $0, \prod$ & 0,0 \\
\hline
\end{tabular}

Because both real estate companies adopt a game attitude, so (investment, investment) becomes the equilibrium of the game, the game is over. Now let's determine the value of $\prod$. From the previous deduction, the extrapolation from table 2 is we can know that the equilibrium profit of real estate developers is $t / 2$. In the case of non-cooperative game, there is only one developer whose profit is $t / 2$; in the case of cooperative game, it is obvious that the profit will be half divided, and the value of $\prod$ will be $t / 4$.

\subsection{Circular city hypothesis}

The above analysis is to abstract the city into a linear city. Now we analyze the situation of circular city, which is closer to the real world. Assuming that consumers are evenly distributed around a circumference of 1 , developers develop projects along the circumference, and all journeys follow the circumference. In this part of the analysis, it is no longer limited to the competition between two developers, but assumes that there are n developers. As mentioned above, consumers need to buy a unit of housing at a transportation cost of t per unit distance (for simplification, we only consider linear transportation costs) and are willing to purchase at a minimum general cost as long as the latter does not exceed the total surplus $\bar{s}$ they obtain from the goods. Each developer develops in only one location. The fixed cost of market entry is f. Once a developer enters and locates at a point in space, the marginal cost is c $(\mathrm{c}<\bar{s})$. In this way, if developer $\mathrm{i}$ enters the market, its profit is $\left(p_{i}-c\right) D_{i}-f_{(} D_{i}$ is the demand function of developer i). If developer does not enter the market, the profit is $0[5]$.

Assuming that $\mathrm{n}$ developers enter the market, they choose a symmetrical development location. There are enough developers in the market (relatively low for f), so there is competition between them. In fact, developer i has only two real competitors, that is, two developers around it. Suppose it chooses price. Under the following conditions: $p_{i}+t x=p+t(1 / n-x)$, there is no difference between consumers who are $x \in(0,1 / n)$ away from Project $\mathrm{i}$ and those who buy Project i from their nearest neighbors. Then, the demand function of the project developed by developer $\mathrm{i}$ is: 


$$
D_{i}\left(p_{i}, p\right)=2 x=\frac{p+t / n-p_{i}}{t}
$$

Developer i maximizes its profits, namely $\max _{p_{i}}\left[\left(p_{i}-c\right)\left(\frac{p+t / n-p_{i}}{t}\right)-f\right]$

\subsection{Game model of circular city hypothesis}

\subsubsection{Non-cooperative game model}

Similarly, it is assumed that only two real estate firms participate in the competition, and in the case of non-cooperative game, there are game models as follows:

Table 3. Non-cooperative game model of circular city hypothesis

\begin{tabular}{|l|c|c|c|}
\hline \multicolumn{4}{|c|}{ Real estate developer 2 } \\
\hline & & Investment & No investment \\
\hline \multirow{2}{*}{ Real estate developer 1} & Investment & 0,0 & $\prod, 0$ \\
\cline { 2 - 4 } & No investment & $0, \prod$ & 0,0 \\
\hline
\end{tabular}

As can be seen from table 3,the game equilibrium is also (no investment, investment) or (investment, no investment), both of which must have an exit. If both real estate companies choose to invest, then they will turn to the next stage of the game.П Value is: $\max _{p_{i}}\left[\left(p_{i}-c\right)\left(\frac{p+t / n-p_{i}}{t}\right)-f\right], \mathrm{i}=1$

\subsubsection{Cooperative game model}

Table 4. Cooperative game model of circular city hypothesis

\begin{tabular}{|l|c|c|c|}
\hline \multicolumn{4}{|c|}{ Real estate developer 2 } \\
\hline & & Investment & No investment \\
\hline \multirow{2}{*}{ Real estate developer 1} & Investment & $\prod / 2, \prod / 2$ & $\prod, 0$ \\
\cline { 2 - 4 } & No investment & $0, \prod$ & 0,0 \\
\hline
\end{tabular}

As can be seen from table 4,(Investment, investment) is still the equilibrium of the game. The game is over here. Now let's determine the value of $\prod$.At this point the value of $\prod$ is no longer $\max _{p_{i}}\left[\left(p_{i}-c\right)\left(\frac{p+t / n-p_{i}}{t}\right)-f\right]$

, Because this formula represents the maximum profit of developers. Of course, if they cooperate, the total profit will remain unchanged, and the maximum value will still be . However, divide it by two and you can know the profits of each developer.

Of course, this is the simplest game assumption. In real life, we must distribute profits according to the cooperation agreement, so the distribution of profits will be different.

\section{Conclusion}

The basic characteristic of real estate development is the fixed position, which determines that the competition among real estate developers is the space competition of fixed position. Therefore, the space competition decides the house price. Because of the spatial distribution of supply and demand, the traditional monopoly competition theory can not explain the spatial competition in the real estate market. Through Hotelling model analysis, this paper shows that transportation cost is an important factor affecting competition and pricing among real estate developers. The role of transportation infrastructure optimization lies in eliminating the differences of real estate between different regions, promoting regional equilibrium of real estate prices and enhancing the value of real estate. When the transportation infrastructure is improved, which makes it convenient to pass between areas with high transportation cost and time cost, the real estate of the two places will have substitution, which will lead to the decline of high house prices and the appreciation of low house prices. The market entry cost and the fixed cost of development also have a significant impact on the competition and pricing of developers. 
The Hotelling model has strict assumptions and does not fully conform to the objective reality. Many scholars have modified the basic assumptions of the Hotelling model to make the spatial location competition theory develop towards general analysis. Hotelling model evolves from pure position game to position price game, and then to position price and strategy price game, which makes the theory of spatial location competition develop steadily. It successfully presents the process and characteristics of spatial competition and positioning among firms, and provides a reference standard for new firms in the market to choose and locate in geographic space[6]. Overall, future research on the Hotelling model may be carried out from the following perspectives:

1) Most of the literature on the location and pricing of the Hotelling model is based on economic considerations. In the future, the concept of real estate design and development will change dramatically, and more functions will be derived, not just for the convenience of living and working. Follow-up research can be combined with cultural creativity, green buildings, healthy real estate, scientific and technological real estate and architecture for the elderly, etc.

2) The research of basic model can also be analyzed from the perspective of vertical differentiation. The combination of horizontal and vertical analysis is more conducive to enriching the content of Hotelling model.

3) With the arrival of the era of big data, location analysis based on the combination of Hotelling model and big data can also be a future research direction.

4) Most scholars have established one-dimensional Hotelling model. Two-dimensional Hotelling model can be used for correlation analysis.

\section{Acknowledgements}

This work was sponsored in part by National Social Science Foundation of China(19XMZ095); Science and Technology Project of Chongqing Municipal Education Commission(KJ1600321); Chongqing Social Science Planning Project(2015QNJJ05).

\section{References}

[1] Hotelling H. (1929) Stability in competition. Economic Journal, 39(153): 41-57.

[2] Reisinger M. (2014) Two-part tariff competition between two-sided platforms. European Economic Review, 68 (2): 168-180.

[3] Ahlin C, Ahlin P D. (2013) Product differentiation under congestion: Hotelling was right. Economic Inquiry, 51(3): 1750-1763.

[4] Doward, Neil. (1982) Recent Developments in the Analysis of spatial competition and their implication for industry Economics. The Journal of Industrial Economics, 31(1): 131-151.

[5] Xu Bing, Zhang Yang. (2017) Complete sequential decision-making of location pricing for two manufacturers based on Hotelling model, Journal of Shandong University, 52(6):1-9.

[6] Xu Bing, Zhang Bin, Wang Ping. (2017) Research on Site Selection and Pricing Competition of Single Manufacturer and Single Retailer Supply Chain. Journal of Fudan, 56(5):619-627. 